\title{
The debate about death: an imperishable discussion?
}

\author{
FÉLIX BACIGALUPO*, DANIELA HUERTA*1 and \\ RODRIGO MONTEFUSCO-SIEGMUND**
}

\author{
* Cognitive Neuroscience Laboratory. Psychiatry Department. Faculty of Medicine. Pontificia Universidad \\ Católica de Chile. \\ ** CENI and ICBM. Faculty of Medicine. Universidad de Chile.
}

\begin{abstract}
In this concise review we discuss some of the complex edges of the concept of death that arose after the notorious advances in science and medicine over the last 50 years, in which the classical cardio-pulmonary criteria have led to the neurological criteria of death. New complicated questions like the definition of death and the operational criteria for diagnosing it have arisen and we think that they are far from being adequately and satisfactorily solved. A number of important issues -like the reliability and differences between cardiopulmonary versus brain based criteria of death, if death is an event or a process, the meaning of integration and irreversibility- have not yet received sufficient attention. Here we have approached the death problem from two (biological) complex system perspectives: the organism level and the cellular-molecular level. We also discuss issues from a third systemic approach, that is, the entire society, thus involving legal, religious, bioethical and political aspects of death. Our aim is to integrate new perspectives in order to promote further discussion on these critical yet frequently neglected issues.
\end{abstract}

\author{
"Dimmed your eyes! \\ Silent your heart! \\ Not a breath's \\ gentle wafting! \\ Must she now in misery \\ stand before you, \\ she who joyously, to marry you, \\ bravely crossed the sea? \\ Too late! \\ Spiteful man!”
}

Tristan und Isolde. Richard Wagner Act III, Scene II.

\section{INTRODUCTION}

Imagine this desperate scene of Wagner's Opera "Tristan und Isolde" changed by the current advances of science and medicine; maybe Isolde could include some of the brain death criteria, like coma and the absence of brainstem reflexes, to assert the death of her beloved Tristan. It could be argued that this is art, and that science and the criteria of death have nothing to do with it. We would say that, on the contrary, it is important to consider the influence that the advances of science in general and medicine in particular have on other disciplines and in everyday life, especially in such dramatic circumstances. For us, children of a materialistic age characterized by an amazing development of sophisticated technology, in which the intensive care techniques are seen as one of its highest achievements, it might be argued without doubt that brain death is death. It is a fact around us, influencing our daily life, thoughts and decisions; it could be understood as a contemporary dogma. The fast life style of our times generally does not allow us to stop and question the grounds from which our truths have been built and in consequence, we are blind to the many controversies and criticisms about brain death, from its philosophical definition to the medical

\footnotetext{
${ }^{1}$ Corresponding author. Marcoleta 391, $2^{\circ}$ Floor. Santiago, Chile. Phone: 56-2-354806. Fax: 56-2-6651951.

E-mail address:dhuerta@puc.cl.
} 
diagnostic tests that confirm it. Yet there is still a great discussion about some fundamental aspects regarding the concept of death. One extensively accepted definition of death is the "permanent cessation of the critical functions of the organism as a whole" (Bernat, 2005). Bernat and colleagues (1981) have distinguished three levels of discussion: the definition or concept of death (a philosophical matter); the anatomical criteria of death (a philosophical/medical matter); and the practical testing which, by way of clinical or complementary examinations, can determine that death has occurred (a medical matter) (Bernat et al., 1981).

Here we will discuss about death, a phenomenon that people in general do not want to talk about, but inevitably will someday confront. We will approach the death problem from two biological complex system perspectives with special attention on the interactions and regulatory processes involved: the organism and cellularmolecular levels. But we will also refer to a third system: the entire society, therefore involving historical, legal, religious, bioethical and political aspects.

THE PROBLEM OF DEATH BEFORE THE

INTRODUCTION OF INTENSIVE MEDICAL CARE

Since the beginning of humankind the most natural sign of life has been movement; with spontaneous respiration being probably the paradigmatic example. The concept of movement as sign of life is called quickening, an old term related to the latin vivus and the greek bios (Dagi and Kaufman, 2001). In old biblical translations, the divine ability to instill life into corpses is described as the ability to quick the dead. According to this concept, the presence of the divine soul or the conjunction of atoms that originated human life was detected through the existence of some minimal movement or spontaneous activity. The idea of quickening was extended to the activity of the heart and lungs and for this reason, cessation of heartbeat and respiration were considered the first "standard" criteria of death (i.e. classical cardio-respiratory criteria of death) (Dagi and Kaufman, 2001). From ancient times to the first half of the $20^{\text {th }}$ century there were no doubts that death was confirmed by the absence of pulse and breathing. Nevertheless, from the seventeenth century onwards scientists, physicians, theologians and the lay public had become preoccupied with premature burial (Ducachet, 1822; Snart, 1824). At the beginning of the eighteenth century, the Resuscitation Movement strove to promulgate and popularize the skills of resuscitation and artificial respiration that had to begin at the moment of loss of spontaneous pulse or respiration (Dagi and Kaufman, 2001). At this "point of resuscitation", it could be considered that the person was either truly or just apparently dead. The difference between real death and apparent death depended whether death was "tested", based on the response to resuscitation: outside the immediate reach of medical care, apparent death equated to death; within the reach of medical care, response to resuscitation meant life and failure of resuscitation categorically meant death (Dagi and Kaufman, 2001).

THE PROBLEM OF DEATH AFTER THE INTRODUCTION OF INTENSIVE MEDICAL CARE

In the 1950 s the poliomyelitis epidemic took place in the United States, with hundreds of people dying from its most dangerous clinical syndrome (the paralytic form) in which patients suffered paralysis of the muscles responsible for ventilation. In this context, the use of the "iron lung", a device that sustained artificial ventilation until the full recovery of the patients, became widespread. A great proportion of these patients maintained consciousness and did not exhibit cognitive impairment, thus being considered in a "critical neardeath but conscious" state. In those days, such medical intervention was considered a "resuscitation" technique and the notorious results obtained thereby motivated the extensive use of artificial 
ventilators in patients with diseases other than poliomyelitis that involved coma or unconsciousness. It was assumed that, as in the cases of poliomyelitis, the body would recover to self-sufficiency after mechanic ventilation. However, some of them did not recover and the event that resulted in cardiopulmonary arrest also resulted in irreversible brain damage. These patients never regained consciousness or the ability to breathe spontaneously, with the consequent dissociation never seen before between "body and brain" functioning. This state was initially described as coma depassé (Mollaret and Goulon, 1959). One factor identified with the irreversibility of brain damage was liquefaction of the cerebral tissue after prolonged mechanical ventilation. This condition is known as "respirator brain", and was considered incompatible with recovery of spontaneous respiration and consciousness.

It is at this point in time that the disintegration of the consensus about death emerges because, as we have described, it became possible to observe the dissociation between the function of the brain and the heart and lungs. The moment of death-until then a reliable and secure fact-was irrevocably questioned. The second half of the $20^{\text {th }}$ century witnessed the surge of the practical uncertainty about death. In this new scenario new questions and problems emerged: for example, ventilatory support did not reliably restore patients to selfsufficiency or to consciousness; the demand for intensive care unit beds outstripped the supply so that there were more patients needing ventilatory support than the health system could afford; finally, heart transplantation had just begun, requiring a precise criterion to declare that the donor was dead, while also avoiding the loss of adequate myocardial function. As these practical problems arose, due mainly to the advances of science and medicine, such disciplines became relevant for the discussion about the definition of death, as had never happened before. An example of this is the allocution of the Pope Pius XII (1957) entitled "The Prolongation of Life", which established that the pronouncement of death was not the province of the church but responsibility of the physician: "It remains for the doctor [...] to give a clear and precise definition of death and the moment of death of a patient who passes away in a state of unconsciousness" (XII, 1977).

After all of these new advances and controversies, in 1968 the Harvard Ad Hoc Committee was conformed, defining the criteria for brain death (1968). The suggestion that brain-based criteria might lead to a new, generally accepted definition, independent of cardio-pulmonary function, led to a general reappraisal of the meaning of death. We agree with Youngner and Arnold that a number of important issues about death have not received sufficient attention, i.e. the meaning of integration, the reliability and differences between cardio-pulmonary versus brain based criteria of death, if death is an event or a process and irreversibility (Youngner and Arnold, 2001). In the following section we turn to these matters with the aim to integrate new perspectives in order to promote further discussion of these critical issues.

THE PROBLEM OF INTEGRATION AND THE CRITERIA OF DEATH

An important concept related with death is the consideration of the organism as a whole, which refers to its unity and functional integrity, not to the simple sum of its parts, thus encompassing the concept of an organism critical system (Korein and Machado, 2004). In this line, Shewmon (1999) proposes that living organisms have an integrative unity, that is, they have at least one emergent holistic-level property. Emergent means that it derives from the mutual interaction of all of the parts, and holistic means that the property is originated only from the whole composite. (Shewmon, 1999). Critical functions are those that are necessary for the organism to work as a whole: control of respiration and circulation, neuroendocrine and homeostatic regulation and consciousness. Some authors propose that these functions 
are ultimately carried out by the brain (Laureys, 2005). However, the persistence of hypothalamic neuroendocrine functions in "whole brain-dead" patients has been advocated against this formulation (Machado, 1999). For Shewmon, the integrative unity of a complex organism involves the cooperative interaction of all of its components, therefore it could not be realized as just the simple coordination imposed by one part upon the others, nor can it be anatomically localized in just one organ (Shewmon, 1999). This author suggests that most of the integrative functions of the brain are not somatic; in fact, most of the integrative functions of the body are not mediated by the brain (e.g. homeostasis, energy balance, maintenance of body temperature). Brain function would be more modulatory than constitutive, increasing the quality and the survival potential of the living organism (Shewmon, 2001).

Death of the whole organism: cardiopulmonary versus brain-based criteria of death

Prior to medical intensive care, there was only one criterion of death: cessation of respiration and circulation, conforming to the cardio-pulmonary criteria. However, as discussed previously, after important scientific advances, alternative criteria based on the ceasing of brain functioning were proposed. In 1968 the criteria of death of the Harvard Committee was published stating that irreversible coma was equal to death (1968). Nowadays, death can be diagnosed in two ways, by cardiorespiratory or neurological criteria. Authors like Laureys (2005) suggest that brain death means human death determined by neurological criteria. Within the "neurological" criteria there are three main sub-criteria: the whole brain, the brainstem and the neo-cortical criteria of death (Laureys, 2005). The whole brain formulation requires bedside demonstration of irreversible cessation of all clinical functions of the brain, and is the most widely accepted. For Bernat (2005), there is a rigorous conceptual basis for regarding whole-brain death as human death based on the biophilosophical concept of the loss of the organism as a whole (Bernat, 2005). The brainstem formulation regards irreversible cessation of clinical functions of the brainstem as not only necessary but also sufficient for the determination of death. In this way, Pallis (1995) argues that the brainstem is the through-station for almost all hemispheric input and output, the centre that generates arousal (which is essential for consciousness), and the centre of respiration (Pallis, 1995). Both criteria suppose that the brain (with its cortical and subcortical structures including the brainstem) has a fundamental role in the integration of the organism. The clinical set of tests for whole brain and brainstem death are identical.

In sum, there are two sets of tests that can be used to ascertain death: neurological and/or cardio-pulmonary; which test is used depends on whether or not the patient is on mechanical ventilation. In non-artificially ventilated patients, physicians evaluate the irreversible absence of heart beat and breathing to declare death, but in patients who are mechanically ventilated, validated neurological tests are used to assure irreversible absence of brain (brainstem) function. As mentioned above, the criteria for brain death is based principally in findings from the clinical examination (coma, apnoea, absence of brainstem reflexes and motor responses); the confirmatory laboratory tests are only required when specific components of the clinical tests cannot be reliably evaluated (The Quality Standards Subcommittee of the American Academy of Neurology, 1995). Such ancillary diagnostic studies include cerebral angiography and transcranial doppler sonography which can be used with a very high sensitivity and specificity to document the absence of cerebral blood flow in brain death (Ducrocq et al., 1998a, Ducrocq et al., 1998b). In this line, radionuclide cerebral imaging like single photon emission computed tomography (SPECT) and positron emission tomography (PET) can show the hollowskull sign, confirming the absence of brain function (Conrad and Sinha, 2003, Laureys 
et al., 2004). The electroencephalogram (EEG) in patients with brain death shows the absence of electrocortical activity with a sensitivity and specificity of $90 \%$ (Buchner and Schuchardt, 1990) and, because of its availability, it has become the preferred confirmatory test for brain death and has been implemented in many countries' guidelines (Wijdicks, 2002, Laureys, 2005). Somatosensory evoked potentials show arrest of conduction at the cervicomedullary level in brain death (Facco and Machado, 2004). Anatomopathology in patients with brain death who are receiving maximal artificial means of support will inevitably end up showing the "respirator brain": surface vasocongestion, subarachnoid haemorrhage, and cortical congestion and haemorrhage (Leestma et al., 1984).

\section{Cortical death}

Brierley et al (1971), Veatch and others suggest that death can be defined by the permanent cessation of those higher functions of the nervous system that demarcate man from the lower primates and other animals. This neocortical or higher brain death definition has its conceptual basis on the premise that consciousness, cognition and social interaction, not the bodily physiological integrity, are the essential characteristics of human life (Brierley et al., 1971, Veatch, 2005). In this line, the neocortical death criterion includes only the permanent loss of neocortical function, not of the whole brain or of the brainstem. As Laureys suggests, clinical and confirmatory tests for neocortical death have never been validated as such (Laureys, 2005). In contrast to brain death (whole brain and brainstem) for which the neuroanatomy and neurophysiology are both well established, anatomopathology, neuroimaging and electrophysiology techniques cannot, at present, determine the presence or absence of human consciousness. Therefore, no accurate anatomical criteria can be defined for a higher brain formulation of death. Moreover, in clinical practice, tests would require the provision of bedside behavioural evidence showing that consciousness has been irreversibly lost. This however implies a strong methodological and philosophical limitation, because consciousness is a subjective first-person experience and clinical evaluation is limited to evaluating patients' responsiveness to the environment (Laureys, 2005). Unlike patients with brain death, patients in a vegetative state can move, breath and open their eyes spontaneously, showing how extremely difficult it is to clinically differentiate between automatic and willed movements (Prochazka et al., 2000). Furthermore, complementary tests for neocortical death would require the confirmation of irreversible loss of all cortical functions; but patients in a vegetative state may show preserved islands of functional pallium or cortex. Recent functional neuroimaging studies have shown limited, but undeniable, neocortical activation in patients in a vegetative state, disproving the idea of complete neocortical death in these patients (Rudolf et al., 1999, Beuthien-Baumann et al., 2005).

Finally, based on the neocortical definition of death, patients in a vegetative state following an acute injury or chronic degenerative disease like Alzheimer's disease, and anencephalic infants, are considered dead. As Serani (1999) suggests, for the "living human" the personal, intellectual, volitive, free and moral life conform the higher and most proper level of ontological manifestation, a level for which the mere organic life represents the lesser and poorer degree of realization. Nevertheless, in an inverse hierarchic view, organic life appears as the primary, radical and unchangeable condition of any ontologically superior manifestation. In this line, Serani proposes that organic life is the nursemaid, the throne, the home for all the others superior manifestations of human life. It is the first to arise and the last to disappear. Human life is expressed organically before the conformation of the tools of superior life and persists beyond their disappearance. The human being is much more than a living organism but it is nothing less than one either (Serani, 1999). 


\section{Death as event versus death as process}

A second rather critical issue in the discussion about death, and which is related to the above considerations, is if death is a clear cut event or a progressive, temporally extended, process. According to the "dead donor rule" for organ transplantation, we cannot take a critical organ from a living person in order to save another, because it means that in the process we are killing somebody. It is clear that considering death as event or death as process is critical to this question. If we consider that death is an event, maybe we will focus in those signs that accurately confirm that a person is dead, and maybe we will use the cardiopulmonary criteria, in which we will diagnose the death of a person through the absence of respiration or heart beating. One extreme position in this line is to wait for the expression of "positive" signs of death like cooling of the body (algor mortis), rigidity (rigor mortis), lividness (livor mortis) and dehydration (Echeverria et al., 2004). On the other hand, we could also consider death as an event if we assume, guided by brain death criteria, that the dead body is artificially maintained by technology. Lizza (2005) proposes that by artificially sustaining brain-dead human bodies or, hypothetically, decapitated human bodies, we intervene in the life history of the organism in such a radical way that we create new kinds of beings, and that we should recognize that the human being or "person" has died. In fact, artificially sustaining a "brain dead" body falls outside the natural or normal course of events; it is more a technological artifact (Lizza, 2005). As Laureys (2005) suggests, brain death would signify death not because it is invariably imminently followed by asystole, but because it is accompanied by irreversible loss of critical cerebral functions and thus it would represent the disintegration of the organism as a whole (Laureys, 2005).

On the other hand, if we assume that death is a process we could consider that the brain death criteria give us a practical tool to determine that the "death cascade" has begun and will inevitably end in death according to cardio-pulmonary criteria. From a thermodynamical perspective, the "point of non-return" occurs if the tendency to the active self-sustainment of the body is irreversibly lost so that entropy will increase as for inanimate objects. In the opinion of Shewmon (2001), the loss of integrative unity involves anatomically a critical level of damage at molecular scales in the complete body; we can see death like a progressive process of energy disorganization. From this point of view, life is the state of an organized system that has a dynamic balance of energy exchange with the environment, and the loss of such balance (point of non-return) would imply the disorganization of the system, inevitably ending in the total disintegration of the organism (Shewmon, 2001).

Until now we have referred to death in an organism level, but we think that we could provide new insights into this issue if we look at the cellular-molecular level. In this line, the death of a cell can be defined as an irreversible loss of plasma membrane integrity. Historically, three types of cell death have been distinguished in mammalian cells by morphological criteria. Type I cell death, better known as apoptosis, is defined by characteristic changes in nuclear morphology, minor changes in cytoplasmic organelles, overall cell shrinkage, blebbing of the plasma membrane and formation of apoptotic bodies that contain nuclear or cytoplasmic material. All of these changes occur before plasma membrane integrity is lost. Type II cell death is characterized by a massive accumulation of two-membrane autophagic vacuoles in the cytoplasm. Type III cell death, better known as necrosis, is often defined in a negative manner as death lacking the characteristics of the type I and type II processes. (Golstein and Kroemer, 2007). Apoptotic cell death is characterized by controlled autodigestion of the cell. Cells appear to initiate their own apoptotic death through the activation of endogenous proteases named caspases, which are classified into 'initiator caspases' (caspases 2, 8, 9 and 10) and 'effector caspases' (caspases 3, 6 and 7). It has been proposed that in the apoptotic model the threshold for 
cell death is dynamically regulated and determined by the combined effects of external and internal survival factors (Thompson, 1995). On the other hand, another kind of cell death, necrosis, can be both fully unregulated and 'programmed'. Necrosis might be programmed in terms of both its course and its occurrence, and this is supported by numerous results. Golstein and Kroemer suggest that the same upstream signal can produce different types of cell death as a function of, in particular, the activation or inhibition of catabolic enzymes in the cell (Golstein and Kroemer, 2007). As we can see, at the cellular level, death is realized as a process.

\section{About irreversibility}

If we consider death as a process, we are confronted with a rather complex issue, that is, to define or pinpoint the moment of irreversibility of death. This is obviously not a trivial issue because we have to be able to predict, with extremely high reliability, that death according to one criterion, say brain death, will be inevitably followed by death diagnosed by cardiopulmonary criteria. In the context of death as a process, it could be argued that a person with brain death has begun an irreversible process of disintegration that could be delayed by artificial means like mechanic ventilation. In this line, one prospective study (1977) supporting the neurocentric criteria of death found that cerebral unresponsiveness, apnoea and an isoelectric electroencephalogram were predictors of death based on cardiopulmonary criteria within 3 months, despite continued ventilatory and cardiac support. However, Shewmon (1998) in a metaanalysis, found 175 cases of patients diagnosed with brain death surviving 1 week or more, with enough information of factors affecting survival capacity on 56 cases. Of these cases, one-half (28/56) survived more than 1 month, nearly onethird (17/56) more than 2 months, seven (13\%) more than 6 months, and four $(7 \%)$ more than 1 year, the record being 14 years. For Shewmon, the tendency to asystole in brain death can be transient and is attributable more to systemic factors than to the absence of brain function per se (Shewmon, 1998).

Evidently, an important aspect is the role and availability of technological advance plays in the determination of irreversibility. For Lizza (2005), we should consider realistic impediments for holding that a patient's condition is irreversible. As the author suggests, to clarify this sense of "irreversibility" it may be helpful to distinguish three factors that can affect the reversibility of either the cessation of cardio-respiratory functions or the cessation of all brain functions: the physical state of the person, factors external to the person, and individual and social decisions. The physical state of the person with respect to "irreversibility" refers to whether a person's physical state is sufficient to prevent the reversibility of cardiorespiratory functions or all brain functions. Factors external to the person refer to whether medical interventions are available to the patient at the time of cardiorespiratory arrest or cessation of all brain functions. Individual and social decisional factors refer to whether decisions have been made by the patient, family, health care providers, or society to obstruct any medical intervention to reverse the cessation of cardio-respiratory functions or brain functions. For example, in a patient with a "do not resuscitate" order, the cessation of cardio-respiratory functions can be said to be irreversible and the patient is beyond the point of spontaneous autoresuscitation. This, even though features of the patient's physical state alone are insufficient to determine irreversibility and the medical technology to resuscitate is available. In this example of Lizza (2005), external factors in the form of a deliberate decision lead to practical restrictions on what can be done to the patient, although there are no technological or physical arguments to consider this situation irreversible (Lizza, 2005).

As Laureys (2005) proposes, the prolonged absence of intracranial blood flow is considered to prove irreversibility based on brain death criteria. On the contrary, the reduced -but not absent- 
cortical metabolism observed in the vegetative state cannot be regarded as evidence for irreversibility according to cortical death criteria, (Schiff et al., 2002, Bernat, 2004). Indeed, fully reversible causes of altered consciousness, such as deep sleep and general anaesthesia, have shown similar decreases in brain function, and the rare patients who have recovered from a vegetative state have been shown to resume near-normal activity in previously dysfunctional associative neocortex (Alkire et al., 1999, Laureys et al., 1999).

At a cellular level one might assume that in apoptosis, caspase activation is the "point of no return' for a cell to die. However, as Kaufmann and Hengartner (2001) discuss, recent studies cast doubt on this assumption. Two studies in $C$. elegans have demonstrated that mutations in genes required to remove 'dead cells' can actually lead to increased cell survival. These studies found that cells expressing maimed CED-3 sometimes started to undergo programmed cell death and then reverted to a normal phenotype when they were not engulfed (Hoeppner et al., 2001, Reddien et al., 2001). This reversibility of cell death has also been reported in growth-factordeprived neurons when caspase activation is inhibited (Martinou et al., 1999, Kaufmann and Hengartner, 2001). In sum, there is contradictory evidence about the irreversibility of the death process, both at global and cellular levels.

\section{LEGAL, RELIGIOUS AND BIOETHICAL PERSPECTIVES}

\section{Legal issues}

Nowadays, the brain death criterion of death is widely accepted throughout the world. However, there are some differences between countries. For example, the brainstem criterion is accepted in the United Kingdom, while in the United States the whole brain criterion is considered. Wijdicks (2002) explored the international practices for diagnosing brain death, obtaining original brain death documents of 80 countries. Legal standards on organ transplantation were present in 55 of 80 countries $(69 \%)$ and practice guidelines for brain death for adults were present in 70 of 80 countries $(88 \%)$. More than one physician was required to declare brain death in half of the practice guidelines. Countries with guidelines specified exclusion of confounders, irreversible coma, absent motor response, and absent brainstem reflexes. Apnoea testing using a $\mathrm{PCO}_{2}$ target was recommended in $59 \%$ of the surveyed countries. Differences were also found in the time of observation and in the required expertise of examining physicians. Confirmatory laboratory testing was mandatory in 28 out of 70 practice guidelines $(40 \%)$. Wijdicks concluded that there is uniform agreement on the neurologic examination with exception of the apnoea test. Nevertheless, other major differences in procedures for diagnosing brain death in adults were also found in this survey (Wijdicks, 2002).

In 1996 the law $\mathrm{N}^{\circ} 19.451$ was promulgated in Chile, establishing the norms for organ transplantation and donation. For Flores et al (2004) this law is a relevant contribution because it defines death by neurological criteria (brain death), incorporating appropriate diagnostic protocols that clearly establish the conditions for diagnosing death. It also permits to establish the person's choice on organ donation during her/his life. However, the authors note that this law also has deficiencies because according to it, brain death criteria are only applicable to those who will be organ donors (Flores et al., 2004). Consequently, according to this law, those who will be donors could be diagnosed dead by brain death criteria, while those who will not, lack the corresponding criteria.

\section{Religious aspects}

As we mentioned previously, the Catholic Church through Pope Pius XII declared that the diagnosis of death was a strictly medical matter. Later, Pope John Paul II recognized the neurological criteria of death and declared that if rigorously applied, they do not seem to conflict with 
the essential elements of a sound anthropology. In other major religions there are similar positions. The Jewish law recognizes the ethical value of organ donation and the Islamic code of medical ethics approved the organ donation as a benefit to society (Flores et al., 2004). Thus, several major religions agree with the neurological criteria of death and organ transplantation.

\section{Bioethics}

Bioethical principles are at the basis of the conception of death and are intrinsically related with organ donation and transplantation. They involve aspects like not using human beings with instrumental purposes. For Tomlinson (1993), the meaning of irreversibility in the definition of death is an ethical one: for him "irreversibility" means that "the possibility of reversal is not ethically significant". According to this author, because there are good ethical reasons for honouring the wishes of the donor, "those medical means for reversing his cardio-respiratory arrest are no longer ethically significant possibilities" (Tomlinson, 1993). In this line, in relation to cases involving "do not resuscitate" orders, despite that from a strictly technological point of view the dying patient's physical condition could be reverted, practical restrictions to perform resuscitation on the patient make it extraordinarily improbable that the cessation of cardio-respiratory functions will be reversed. Even though it may be physically possible to resuscitate some "do not resuscitate" patients, they are correctly declared dead soon after cardiac arrest, because their cardio-respiratory functions have irreversibly ceased, that is, it is highly unlikely that their functions will resume, given their physical state and recognition of the patient's wish not to be resuscitated (Tomlinson, 1993, Lizza, 2005). On this issue, the Pontifical Academy for Life stated that the approach to the gravely ill and the dying must be inspired by the respect for the life and dignity of the person. It should pursue the aim of making proportionate treatment available but without engaging in any form of "overzealous treatment". One should accept the patient's wishes when it is a matter of extraordinary or risky therapy which he is not morally obliged to accept. One must always provide ordinary care (including artificial nutrition and hydration), palliative treatment, especially the proper therapy for pain, while always keeping the patient informed. At the approach of death, which appears inevitable, "it is permitted in conscience to take the decision to refuse forms of treatment that would only secure a precarious and burdensome prolongation of life" accepting the natural conclusion of life (Vial Correa and Sgreccia, 2000).

In relation to the principles of bioethics, the principle of autonomy must be reflected in the informed consent and the statement of the will for donation of patients and "do not resuscitate" orders. The principle of beneficence relates to human solidarity and compassion in the decision of donation and the non-maleficence principle could be reflected in the security of procedures (Flores et al., 2004). It is important to take into account the deep meaning of the organ donation that deserves the higher respect to the dead body of the person who decided in life to donate himself.

\section{CONCLUSION}

In this concise review we have discussed some of the complex edges of the concept of death. Of course, these issues are intimately related with the notorious advances in science and medicine over the last 50 years. New complicated questions therefore are posed, from the definition of death to the operational criteria for diagnosing it, and answering them requires from philosophy to physiology. We can see that some of these problems are far from being adequately and satisfactorily solved, and there is an important debate around them. We have tried to approach the death problem from two biological complex systems perspectives in which interactions and regulatory processes are paradigmatically involved: the organism level and the cellular-molecular one. Of 
course, we could realize that there is a third systemic approach: the entire society, involving the legal, religious, bioethical and political aspects.

Historically, the classical cardiopulmonary criteria have led to the neurological criteria of death. It could be argued that the circulation-respiration proposal signals in a more accurate way the death phenomenon if we dimension it as a clear-cut event, but if we look at death as a process of disintegration, then brain death can be viewed as the beginning of this irreversible chain. However, there is a great discussion about the real irreversibility of this process whether at a human dimension or at a cellular one. If we attend to aspects like the practical testing of death it could be realized the difficulty of demonstrating the theoretical concept of circulation-respiration death; nowadays it is almost unaffordable to prove the ceasing of circulation at the cellular level or the end of respiration at the mitochondrial level. Instead of it, cardiopulmonary and neurological criteria of death can be clinically tested in patients.

On other hand, we have to take into account that despite the fact that technological advances allow us to maintain life artificially and that the notion of irreversibility may therefore change depending on available technological support, the goal of medical care must be to preserve human dignity at any moment, including the moment of death. In this line, it is fundamental to respect the will of the patient and family concerning conducts such as orders of no resuscitation and to avoid therapeutic cruelty that goes against human dignity. In this context, we believe that there are more important things than mere technical advances or the biological possibility of recovery to declare some situation reversible or not.

From a practical point of view, the scientific improvement of medicine has led to important questions, related to organ transplantation and artificial life-sustaining, in intensive care units that constitute "everyday situations" for physicians and the patient's family, requiring clear and adequate answers. As we have seen, only brainstem and whole-brain criteria have good anatomical and clinical support, and are accepted in most countries. In contrast, the cortical death criterion does not have scientific support, besides the ethical problems that it raises. It could be suggested that the neurocentric concept of brain death is no more than utilitarian criteria for defining death. However, we must also consider that scientific progress has opened the way to medical "miracles" like organ donation and transplantation that without this concept would be difficult to afford. In order to define the limits of intensive care unit treatment and organ donor transplantation policies, it is necessary to have accurate and dependable criteria of death; nobody should interrupt a life in order to save another.

Finally, we have to consider that death is a natural and inevitable event and although patients, their families and physicians have the right to fight against disease, some day the moment of the disintegration will arrive. Independently of every human being's beliefs, it is important to be conscious that death is no defeat, but a defining part of the nature of life.

\section{ACKNOWLEDGEMENTS}

This work was financed by a MECESUP doctoral full scholarship awarded to FB and a CONICYT doctoral full scholarship awarded to DH.

We would like to thank Diego Cosmelli and Francisco Aboitiz for revisions and comments on previous versions of this manuscript. We would like also to thank Adrián Palacios and Diego Cosmelli, chairs of the workshop "Networks in Cognitive Systems / Trends and Challenge in Biomedicine: From Cerebral Process to Mathematical Tools Design" at the Instituto de Sistemas Complejos de Valparaíso (ISCV).

\section{REFERENCES}

A definition of irreversible coma. Report of the Ad Hoc Committee of the Harvard Medical School to Examine the Definition of Brain Death. (1968) JAMA 205: 337-340 
An appraisal of the criteria of cerebral death. A summary statement. A collaborative study. (1977) JAMA 237: 982-986

ALKIRE M, POMFRETT C, HAIER R, GIANZERO M, CHAN C, JACOBSEN B, FALLON J (1999) Functional brain imaging during anesthesia in humans: effects of halothane on global and regional cerebral glucose metabolism. Anesthesiology 90: 701-709

BERNAT J (2004) On irreversibility as a prerequisite for brain death determination. Adv Exp Med Biol 550: 161-167

BERNAT J (2005) The concept and practice of brain death. Prog Brain Res 150: 369-379

BERNAT J, CULVER C, GERT B (1981) Definition of death. Ann Intern Med 95: 652

BEUTHIEN-BAUMANN B, HOLTHOFF V, RUDOLF J (2005) Functional imaging of vegetative state applying single photon emission tomography and positron emission tomography. Neuropsychol Rehabil 15: 276282

BRIERLEY J, GRAHAM D, ADAMS J, SIMPSOM J (1971) Neocortical death after cardiac arrest. A clinical, neurophysiological, and neuropathological report of two cases. Lancet 2: 560-565

BUCHNER H, SCHUCHARDT V (1990) Reliability of electroencephalogram in the diagnosis of brain death. Eur Neurol 30: 138-141

CONRAD G, SINHA P (2003) Scintigraphy as a confirmatory test of brain death. Semin Nucl Med 33: 312-323

DAGI FT, KAUFMAN R (2001) Clarifying the discussion on brain death. J Med Philos 26: 503-525

DUCROCQ X, BRAUN M, DEBOUVERIE M, JUNGES C, HUMMER M, VESPIGNANI H (1998a) Brain death and transcranial Doppler: experience in 130 cases of brain dead patients. J Neurol Sci 160: 41-46

DUCROCQ X, HASSLER W, MORITAKE K, NEWELL D, VON REUTERN G, SHIOGAI T, SMITH R (1998b) Consensus opinion on diagnosis of cerebral circulatory arrest using Doppler-sonography: Task Force Group on cerebral death of the Neurosonology Research Group of the World Federation of Neurology. J Neurol Sci 159: 145-150

ECHEVERRIA C, GOIC A, LAVADOS M, QUINTANA C, ROJAS A, SERANI A, VACAREZZA R (2004) The diagnosis of death. Rev Med Chil 132: 95-107

FACCO E, MACHADO C (2004) Evoked potentials in the diagnosis of brain death. Adv Exp Med Biol 550: 175187

FLORES J, PEREZ M, THAMBO S, VALDIVIESO A (2004) Brain death, bioethics and organ transplantation. Rev Med Chil 132: 109-118

GOLSTEIN P, KROEMER G (2007) Cell death by necrosis: towards a molecular definition. Trends Biochem Sci 32: 37-43

HOEPPNER D, HENGARTNER M, SCHNABEL R (2001) Engulfment genes cooperate with ced-3 to promote cell death in Caenorhabditis elegans. Nature 412: 202-206

KAUFMANN S, HENGARTNER M (2001) Programmed cell death: alive and well in the new millennium. Trends Cell Biol 11: 526-534

KOREIN J, MACHADO C (2004) Brain death: updating a valid concept for 2004. Adv Exp Med Biol 550: 1-14

LAUREYS S (2005) Science and society: death, unconsciousness and the brain. Nat Rev Neurosci 6: 899-909

LAUREYS S, LEMAIRE C, MAQUET P, PHILLIPS C, FRANCK G (1999) Cerebral metabolism during vegetative state and after recovery to consciousness. J Neurol Neurosurg Psychiatry 67: 121-122
LAUREYS S, OWEN A, SCHIFF N (2004) Brain function in coma, vegetative state, and related disorders. Lancet Neurol 3: 537-546

LEESTMA J, HUGHES J, DIAMOND E (1984).Temporal correlates in brain death. EEG and clinical relationships to the respirator brain. Arch Neurol 41: $147-152$

LIZZA J (2005) Potentiality, irreversibility, and death. J Med Philos 30: 45-64

MACHADO C (1999) Consciousness as a definition of death: its appeal and complexity. Clin Electroencephalogr 30: 156-164

MARTINOU I, DESAGHER S, ESKES R, ANTONSSON B, ANDRÉ E, FAKAN S, MARTINOU J (1999) The release of cytochrome $\mathrm{c}$ from mitochondria during apoptosis of NGF-deprived sympathetic neurons is a reversible event. J Cell Biol 144: 883-889

MOLLARET P, GOULON M (1959) The depassed coma (preliminary memoir).]. Revue Neurologique 101: 3-15

PALLIS C (1995) Further thoughts on brainstem death. Anaesth Intensive Care 23: 20-23

PROCHAZKA A, CLARAC F, LOEB G, ROTHWELL J, WOLPAW J (2000) What do reflex and voluntary mean? Modern views on an ancient debate. Exp Brain Res 130: 417-432

REDDIEN P, CAMERON S, HORVITZ H (2001) Phagocytosis promotes programmed cell death in $C$. elegans. Nature 412: 198-202

RUDOLF J, GHAEMI M, GHAEMI M, HAUPT W, SZELIES B, HEISS W (1999) Cerebral glucose metabolism in acute and persistent vegetative state. $\mathrm{J}$ Neurosurg Anesthesiol 11: 17-24

SCHIFF N, RIBARY U, MORENO D, BEATTIE B, KRONBERG E, BLASBERG R, GIACINO J, MCCAGG C, FINS J, LLINAS R, PLUM F (2002) Residual cerebral activity and behavioural fragments can remain in the persistently vegetative brain. Brain 125: $1210-1234$

SERANI A (1999) La "muerte" encefálica y la determinación práctica de la muerte: otra opinión disidente. Cuadernos de Bioética (Santiago de Compostela, España) X: 149-159

SHEWMON D (1998) Chronic «brain death» Meta-analysis and conceptual consequences. Neurology 51: 15381545

SHEWMON D (1999) Disputed question \#1: Is it reasonable to use as basis for diagnosing death the UK protocol for the clinical diagnosis of "brain-stem death"? In: Issues for a Catholic Bioethic Proceedings of the International Conference to celebrate the Twentieth Anniversary of the foundation of the Linacre Centre(Gormally, L., ed), pp 315-333. London

SHEWMON D (2001) The brain and somatic integration: insights into the standard biological rationale for equating "brain death" with death. J Med Philos 26: $457-478$

The Quality Standards Subcommittee of the American Academy of Neurology (1995) Practice parameters for determining brain death in adults (summary statement). Neurology 45: 1012-1014

THOMPSON C (1995) Apoptosis in the pathogenesis and treatment of disease. Science 267: 1456-1462

TOMLINSON T (1993) The irreversibility of death: reply to Cole. Kennedy Inst Ethics J 3: 157-165

VEATCH R (2005) The death of whole-brain death: the plague of the disaggregators, somaticists, and mentalists. J Med Philos 30: 353-378

VIAL CORREA J, SGRECCIA E (2000) The Dignity of the Dying Person: Proceedings of the Fifth Assembly 
for the Academy for Life. Vatican: Libreria Editrice Vaticana

WIJDICKS E (2002) Brain death worldwide: accepted fact but no global consensus in diagnostic criteria. Neurology 58: 20-25

XII PP (1977) The prolongation of life. In: Ethics in medicine: Historical perspectives and contemporary concerns (al., S. R. e., ed): Cambridge, MA: MIT Press.

YOUNGNER SJ, ARNOLD RM (2001) Philosophical debates about the definition of death: who cares? J Med Philos 26: 527-537 